\title{
Construction and validation of a nursing care protocol in anesthesia ${ }^{1}$
}

\author{
Cassiane de Santana Lemos ${ }^{2}$ \\ Vanessa de Brito Poveda ${ }^{3}$ \\ Aparecida de Cassia Giane Peniche ${ }^{4}$
}

Objective: To construct and validate a nursing care protocol in anesthesia. Method: methodological study of face and content validation, judging clarity, relevance, pertinence and comprehensiveness of a care protocol, elaborated from the integrative review of previous literature and based on the conceptual model of assistance perioperative nursing of Castellanos and Jouclas. The protocol was evaluated by five anesthesiologists and nurses from the surgical center. The results were analyzed through the content validity index. Results: among the 119 items assessed by experts, $11(9.2 \%)$ instrument items presented content validity index of $<80 \%$ and were changed. The items with disagreement were related to the selection and availability of materials and equipment, especially before anesthetic induction. The content validity index, obtained for the different items, proposed after the amendments mentioned, ranged from 80 to $100 \%$, in the three periods of anesthesia, indicating the proper validity of the proposed content. Conclusion: the nursing care protocol in anesthesia was considered valid.

Descriptors: Anesthesia; Nursing Care; Operating Room Nursing; Perioperative Nursing; Patient Safety; Checklist.

\footnotetext{
Paper extracted from Master's Thesis "Assistência de enfermagem no procedimento anestésico: protocolo para segurança do paciente", presented at Escola de Enfermagem, Universidade de São Paulo, São Paulo, SP, Brazil.

2 MSc, Doctoral Student, Escola de Enfermagem, Universidade de São Paulo, São Paulo, SP, Brazil, Nurse, Surgery Center, Hospital Sirio Libanes, São Paulo, SP, Brazil.

3 Post-doctoral degree, Professor, Escola de Enfermagem, Universidade de São Paulo, São Paulo, SP, Brazil.

${ }^{4}$ PhD, Professor, Escola de Enfermagem, Universidade de São Paulo, São Paulo, SP, Brazil
}

How to cite this article

Lemos, CS, Poveda, VB, Peniche, ACG. Construction and validation of a nursing care protocol in anesthesia. Rev. Latino-Am. Enfermagem. 2017;25:e2952. [Access 8345.2143.2952. ]; Available in: monthday year DOI: http://dx.doi.org/1518- 


\section{Introduction}

Anesthesia allows the patient comfort during surgery, once the choice of the anesthesia category is based on the type, duration and approach required during the surgical procedure, associated with the clinical, mental and psychological conditions of the patient. Thus, the types of anesthesia are classified in general, regional and sedation ${ }^{(1)}$.

General anesthesia is necessary for procedures that require complete immobility and unconsciousness. It can be classified in three ways, defined as total venous, when only venous drugs are infused, such as propofol and etomidate, general inhalation, when administration of inhalational anesthetics like sevoflurane, desflurane. The association between venous and inhalational anesthetics is defined as general balanced anesthesia ${ }^{(1-2)}$.

The general anesthesia is constituted by the reversible unconsciousness, immobility, analgesia and autonomic reflex block, whose components are hypnosis, analgesia, muscle relaxation and neurovegetative block $^{(2)}$.

Hypnosis is characterized by suppression of consciousness, obtained through the use of inducing agents such as midazolam, propofol and etomidate. Analgesia consists of the relief or absence of pain by the use of drugs such as opioids and anti-inflammatories. Muscle relaxation occurs through the reduction of muscle tone, with the administration of relaxants such as succinylcholine, atracurium and rocuronium. The neuro-vegetative block occurs after adequate hypnosis and analgesia, with an attenuated response of the autonomic nervous system to the surgical stimulus, such as changes in heart rate, blood pressure and sweating ${ }^{(2)}$.

Regional anesthesia is selected for surgical procedures that address upper or lower limbs, abdomen or pelvic region. It can be performed by epidural nerve block, subarachnoid or plexus nerve block, with the administration of local anesthetics such as xylocaine, ropivacaine ${ }^{(1)}$. The association between general and regional anesthesia is defined as combined anesthesia.

Sedation is aimed at patient comfort in small or ambulatory surgical procedures, contributing to the reduction of anxiety, analgesia, decreased movement and maintenance of hemodynamic stability, mainly respiratory pattern and cardiovascular function ${ }^{(1,3)}$.

Adverse events related to health care and patient safety endangerment originate from human error, lack of teamwork and organizational failures ${ }^{(4)}$. Better communication and collaboration among professionals may reduce the risk of morbidity associated with the care of the surgical patient ${ }^{(5)}$. In this context, health care planning, consisting of physicians, nurses and anesthesiologists, is essential to reduce the risks of morbidity and mortality during the anesthetic-surgical procedure, thus promoting patient safety.

Studies indicate that adverse events related to anesthesia involve mainly the respiratory system, cardiovascular system, errors in the execution of regional blocks, equipment and device failures, adverse reactions to medications and lesions related to surgical decision $^{(6-7)}$.

The events of the respiratory system are caused by intubation difficulty, inadequate ventilation and oxygenation, aspiration, early extubation and airway obstruction(6-7).

Concerning the cardiovascular system, adverse events are characterized by hemorrhages, bleeding, hydroelectrolytic imbalances and stroke. Equipment and device failures include the use of central and peripheral catheters, anesthesia equipment, burns and fires caused by the use of electric scalpel and thermal blanket ${ }^{(6-7)}$.

Adverse drug reactions are due to incorrect dose administration and inadequate analgesia(6-7).

The main events in regional blocks are accidental dural puncture, high blockade, cardiac arrest, inadequate analgesia, trauma and catheter retention ${ }^{(6-7)}$.

It should be noted, however, that the mortality risk associated with the anesthetic-surgical procedure has been reduced in the last 50 years due to initiatives for patient safety in anesthesia, which produced a higher quality of perioperative care ${ }^{(8-9)}$.

These initiatives involved the advancement of training, certification and education of professionals for teamwork, development of medications and techniques, improvement of monitoring standards, greater quality in the risk assessment of the patient for surgery, along with the standardization behaviors through care protocols ${ }^{(8-9)}$.

For the same purpose of care, the health care security, the American Committee on Quality and Health Care of the Institute of Medicine (IOM) presented, in 1999, the report To err is human: building a safer health system, proposing the governmental creation of a patient safety center that defined national goals for promoting safety and preventing errors related to health care ${ }^{(10)}$.

As a result of mortality and morbidity rates caused by surgical procedures, in 2002, The National Assembly of 
World Health Organization (WHO), released a resolution aimed at safety during anesthetic-surgical interventions, establishing standards of quality health services, including the implementation of safe anesthesia(11).

The Safe Surgeries Saves Lives program was launched in 2008 by the WHO, with the development of a checklist that directed the assistance performed before the anesthetic induction periods, surgical incision and removal of the operating room ${ }^{(11-12)}$.

The checklist, among several actions, provides for the anesthetic procedure, the checking of the functioning, availability of necessary equipment and materials, patient identification, verification of available tests, evaluation of risks associated with difficult airway via and blood loss ${ }^{(11-12)}$.

It has been shown in studies that the application of the checklist was recognized by health professionals as an important instrument for the prevention of errors, increase of patient safety and assurance of greater assertiveness in inter-professional communication, which enables the previous assessment of the risks and behavior decisions for damage prevention. Thus, there was a reduction of postoperative complications among patients undergoing elective and emergency surgeries, with the reduction in the reporting of adverse health events ${ }^{(13-16)}$.

Therefore, the care protocols, that is, the definition of a specific assistance/care situation, describing details about the operational actions and specifications about the mode of execution and professional execution, are instruments that can reduce the variability of conduct among the professionals involved in health care, to promote greater security for the patient and for the professional, to allow process and outcome indicators to be developed, to improve the quality of care and the rational use of resources ${ }^{(17)}$.

The behaviors recommended in the care protocols must be clear and accurate as to the expected results, to facilitate the use orientation and the understanding by the professionals ${ }^{(18)}$, besides being reviewed periodically, considering the local reality or application institution.

The construction of protocols must be based on scientific evidence, according to their levels of recommendation, based on the elements of quality, quantity and consistency of the reviewed studies(18).

The quality element corresponds to the set of evaluations of individual studies, considering the reduction of errors and bias. The quantity involves the number of studies, sample size or representative power.
The consistency element is equivalent to the degree of similar results in different study designs ${ }^{(18)}$.

In Brazil, according to article $4^{\circ}$ of Law 12,842 of July $10^{\text {th }}, 2013$, the execution of deep sedation, anesthetic blocks and general anesthesia are private activities of the physician(19).

Regarding nursing, the world reality differs from the national one, with different levels of nursing autonomy in the anesthetic procedure. In the United States, there is a specialty of anesthesia in nursing, with certification $^{(20)}$ and defined care standards, which allow the planning and execution of all anesthetic procedures by the nurse(21)

The American nurse who holds the title of specialist in anesthesia conducts nursing undergraduate course and specialization courses of two to three years to obtain professional certification, which must be revalidated every two years ${ }^{(20)}$. The professional can act in a freelance/self-employed, or in anesthesia groups, composed of nurses and/or physicians.

The American nurse responsibilities include preanesthetic evaluation, application of a consent form for the procedure, preparation of the anesthesia plan in any type of procedure, insertion of invasive devices for hemodynamic monitoring, administration of drugs for induction and maintenance of anesthesia, control of the airways and ventilatory pattern during surgery ${ }^{(21)}$.

In some European countries, such as France, Bulgaria and Switzerland, the anesthetist nurse performs certification courses from one to three years, and can perform anesthesia, monitoring and insertion of invasive devices, through defined protocols and under the direct or indirect supervision of medical anesthesiologists(22).

In Brazil, unlike other countries, nurses do not have specific legislation that allows them to act in anesthesia care, with the same autonomy already seen in the countries mentioned.

Thus, after the undergraduate course in nursing, the Brazilian nurse can choose the nursing specialization in surgical center, recovery room and sterilization central supply offered by different public and private educational institutions. It is necessary to emphasize that the absence of specialization does not prevent the Brazilian nurses from working in a surgical center. However, many health institutions require specialization courses and/or professionals with experience in perioperative care.

Therefore, the Brazilian surgical center nurse acts in the planning, management, execution of care and leadership of the nursing team ${ }^{(23-25)}$. 
Care planning is performed by applying the nursing process, called the Perioperative Nursing Care System(26). Among the nurse's management activities is the control of equipment and materials required for the anesthetic-surgical procedure, management of the rooms for procedures, and supervision of activities and care performed by nursing technicians ${ }^{(24-25)}$.

The execution of the surgical patient care includes intraoperative monitoring, administration of drugs and blood components, bladder catheterization, assistance during anesthesia and surgical positioning, infection control through the availability of sterile materials and antisepsis measures(24-25).

Regarding anesthesia care, the surgical center nurse acts in the planning of materials and equipment required, according to the type of anesthesia, patient monitoring, intubation monitoring and ventilation control during anesthetic induction, helps in the control of signs endotracheal aspiration and transport of the patient in the anesthesia reversal phase ${ }^{(27)}$.

However, there is no anesthesia care standard for Brazilian nursing professionals, so each institution performs a different practice and care varies according to the interaction between the anesthesiologist and the nursing team.

The surgical center nurse encounters difficulties in the execution of the nursing process, due to the demand of the health institutions for the fulfillment of their assistance, administrative and managerial role. The difficulty is aggravated by the fact that health institutions do not understand the importance of the nurse's role in assisting the surgical patient, leading to the misuse of assistance for managerial function(28).

Therefore, in order for nurses in a surgical center to perform their role of care in a relevant way, it is necessary to master the scientific knowledge and specificities of the changes generated by anesthesia and surgery, for adequate care planning and evidence of the significant role in the health team.

Thus, in this study the objective was to construct and validate a nursing care protocol in anesthesia.

\section{Method}

This is a methodological study of face validation and nursing care protocol content in anesthesia, based on results obtained in an earlier integrative review, evaluating the actions and care performed by the nursing team in the operating room during the anesthetic procedure $^{(29)}$.
In order to construct the instrument, initially, the American and European anesthetist nurses standards(21,30-31) were observed, considering the Brazilian nursing professional practice law(32), as a basis for structuring the proposed interventions together with the care suggested by the WHO Safe Surgery Checklist ${ }^{(11-12)}$.

In accordance to the mentioned above, the theoretical framework that guided the construction of the care protocol was the conceptual model of perioperative nursing care, proposed by Castellanos and Jouclas ${ }^{(26)}$, which claims the care on the surgical patient in five stages: preoperative evaluation, identification of problems, care planning, implementation of nursing care in the intraoperative period and postoperative evaluation.

Considering the specificity of the proposed instrument, the stages proposed by the conceptual model of perioperative care were structured in three periods of anesthesia care: before induction (organize), induction of anesthesia (assist) and reversal (check).

The period before anesthetic induction consisted of interventions to organize the materials and equipment required for anesthesia. The period of anesthetic induction included direct assistance to the patient care and support to the anesthesiologist. In the reversal period, interventions were defined to check vital signs and record of the care performed.

The first version of the protocol was composed of interventions, involving the three assistance periods, evaluated by a group of five experts, regarding content validity criteria, clarity of items, relevance and completeness of content ${ }^{(33)}$.

The modifications of the interventions were performed regarding the presentation and structure, considering the result of the calculation of the Content Validity Index (CVI) for each intervention and suggestions of the experts.

The main changes suggested were the improvement of the writing of the items, especially in the pre-induction period, and separation of materials and equipment into distinct items, so that the professional only indicates the devices related to the type of surgery that will be performed(33).

In the induction period, the judges suggested revisions of the items regarding nursing notes and records, avoiding duplication of information, checking the patient's history and allergies directly in the medical chart, as well as reviewing the care of the 
anesthesiologist, such as assessment of ventilation and venous puncture(33).

Before the suggestions, a second version of the care protocol was elaborated, with changes in the items regarding the appearance and form of presentation, followed by a new stage of face and content validation by five specialists.

In the second version of the care protocol, brief orientation of the objectives and form of completion of the instrument preceded the described periods. Following, the nursing interventions for each period were described.

The total validity of an instrument is measured by face, content, construct and criterion-related validity ${ }^{(34)}$. In this study, we sought to reach the first validation stages, that is, the structure and content of the protocol elaborated, through the evaluation by the judges of each item referring to its clarity, adequacy, relevance and completeness of content.

The validity of face represents how much a measure seems to be related to the specific content of the evaluated instrument, that is to say, if the content is understood by whom uses the instrument ${ }^{(34)}$. For the face evaluation, in this study, experts answered whether the graphic presentation, the orientation on the form of filling and readability, according to the sequence of presentation of the items, were adequate in the constructed protocol.

Content validity consists of representativeness level of the concept that the instrument intends to measure and provides the items evaluation, according to clarity, relevance, pertinence and comprehensiveness of content(35).

Clarity evaluates whether the construction of the items of the instrument, as the written form, allows adequate reading and promotes understanding of the content. The relevance indicates how the item represents the content that is being measured. Pertinence considers whether items of the instrument are suitable and specific to the assessment content. The completeness of content shows whether the instrument encompasses all items related you want to measure ${ }^{(35)}$.

Each item of the Protocol was scored from one to five, according to Likert type scale: (five) totally agree, (four) I agree, (three) neither agree nor disagree, (two) disagree, (one) totally disagree. On items where disagreement was found, the experts could suggest modifications regarding the proposed content.
The Likert scale is used to measure the opinions, beliefs or attitudes of the respondents of a questionnaire or instrument, through a sequence of affirmations that allows different levels of agreement. Depending on the research phenomenon and the researcher's objectives, odd or pair number of response options may accompany each statement, and responses vary from totally disagree to totally agree ${ }^{(35)}$.

The researcher made e-mail contact with the experts and sent an electronic questionnaire (Google Docs), a presentation letter and the assistance protocol, defining the objectives of the study, instructions on the completion and importance of document evaluation by the experts.

In the scientific literature, it is recommended that the number of specialists selected varies between three and ten individuals(36-37), five is considered to be suitable for evaluation of the agreement ${ }^{(38)}$.

The selection of experts may vary according to the time of clinical experience of the participants, publications and specialization in the area of the research phenomenon, so, in this study, the experts were selected for their work as researchers/specialists in the field of anesthesiology and/or perioperative nursing.

At the end of the protocol evaluation by the expert group, the data were treated and analyzed by the CVI, which measures the proportion or percentage of agreement among experts on certain items of an instrument ${ }^{(39)}$.

In this study, the highest scores were adopted for the CVI calculation, that is, responses (four) agree and (five) totally agree for each item, divided by the total number of specialists, excluding values from one to three. The acceptable agreement rate for this proportion was defined as $80 \%$ or higher ${ }^{(40)}$, with questions modification for those that did not reach this rate, according to the experts' suggestions, and a new round of evaluation.

This study was approved by the Research Ethics Committee of the Nursing School of the University of São Paulo, under no 612310.

\section{Results}

The care protocol was evaluated by five specialists, four nurses and one anesthesiologist. Among the professionals, two are nursing professors and work in public education institutions, two nurses working at surgical center and one is a coordinator of private anesthesia service. 
The age of the experts varied between 29 and 58 years (average of 41 years) and the average time of professional training was 17 years.

Regarding face validity, all experts stated that the graphical presentation, the guidelines for the filling form and the sequence structure of the items allowed an adequate reading and understanding of the care to be performed by the nurse during the anesthetic procedure.

Among the 119 items evaluated, only 11 (9.2\%) items of the protocol presented CVI $\leq 80 \%$, as presented in Table 1, and they were modified according to the experts' suggestions. There were no items excluded.

Most of the disagreements among the specialists occurred in the period before anesthetic induction, in which the evaluated items presented CVI ranging from 40 to $100 \%$ in the clarity criteria, from 80 to $100 \%$ in relevance, from 60 to $100 \%$ in pertinence and from 40 to $100 \%$ in completeness of content.

Regarding the item of operation of the anesthesia equipment, the experts considered the need for guidance on the test of the equipment and the evaluation of its operation, taking into account the diversity of brands and models. In addition, experts recommended the establishment of a minimum number of available breathing circuit and modification of the wording of the item, definition of the saturation percentage (color modification) of soda lime and the need for exchange (Table 1).

The experts suggested the definition of the type of blood pressure cuff, according to the physical characteristics of the patient, together with the establishment of the Multiparameter monitor alarm, according to the patient's age group (adult or child) (Table 1).

Regarding airway materials, there were considerations regarding the separation of the endotracheal tube of different sizes, according to the patient's physical characteristics and type of surgery (Table 1).

The experts stated that for the clarity and completeness of content of the items describing the intubation materials, it is necessary to choose the patient's face mask and gastric tube, considering characteristics such as age and weight (Table 1).

In the items on difficult airway, experts advised to better define the parameters of choice of materials such as the tracheostomy tube and the esophagus-tracheal tube (combitube) (Table 1 ).

In the period of anesthetic induction, the evaluated items presented CVI from 80 to $100 \%$ in the criteria of clarity, relevance and pertinence and CVI from 60 to $100 \%$ in the completeness of content. The only item with disagreement was patient monitoring, for which it was suggested to explain the type of sensor used for temperature verification (Table 1 ).

In the period of anesthesia reversal, there was no change in the initially proposed items, which presented CVI from 80 to $100 \%$ in the criteria of clarity and completeness of content, $100 \%$ in the criteria of relevance and pertinence.

Following the evaluation of the experts' suggestions, the items were modified and submitted to a new round of evaluations and the CVI was recalculated, as presented in Table 2.

Figure 1 shows the final version of the care protocol. 
Table 1 - Content validity index of less than $80 \%$ of nursing care, in the period before induction and maintenance, according to evaluation criteria. São Paulo, SP, Brazil, 2016

\begin{tabular}{|c|c|c|c|c|}
\hline \multirow{2}{*}{ Item / nursing care } & \multicolumn{4}{|c|}{ Evaluation criteria } \\
\hline & Clarity & Relevance & Pertinence & Completeness \\
\hline \multicolumn{5}{|l|}{ Before induction } \\
\hline \multicolumn{5}{|l|}{ A) Operation of anesthesia equipment } \\
\hline 1) Perform anesthesia equipment test & 40 & 100 & 100 & 60 \\
\hline $\begin{array}{l}\text { 2) To evaluate the availability of breathing circuit reserves according to } \\
\text { the age range of the patient }\end{array}$ & 80 & 80 & 80 & 60 \\
\hline 3) Evaluate the color of soda lime & 40 & 100 & 60 & 40 \\
\hline 4) Blood pressure cuff & 80 & 100 & 80 & 60 \\
\hline 5) Multi-Parameter Monitor Alarm & 60 & 100 & 100 & 60 \\
\hline \multicolumn{5}{|l|}{ D) Airway material } \\
\hline $\begin{array}{l}\text { 6) Separate endotracheal tube according to the patient's age range, } \\
\text { consider the availability of three different numbers }\end{array}$ & 60 & 100 & 100 & 60 \\
\hline \multicolumn{5}{|l|}{ E) Organize materials for intubation } \\
\hline 7) Facial mask according to patient's age group & 60 & 100 & 100 & 80 \\
\hline 8) Nasogastric tube & 80 & 100 & 80 & 60 \\
\hline \multicolumn{5}{|l|}{ F) Difficult airway } \\
\hline 9) Availability of tracheostomy cannula & 80 & 80 & 80 & 60 \\
\hline 10) Esophageal-tracheal tube(combitube) availability & 100 & 80 & 80 & 60 \\
\hline \multicolumn{5}{|l|}{ Anesthetic induction } \\
\hline \multicolumn{5}{|l|}{ C) Monitor the patient with } \\
\hline 11) Temperature & 80 & 100 & 100 & 60 \\
\hline
\end{tabular}

Table 2 - Content validity index of nursing care, modified in the period before induction and anesthetic induction, according to evaluation criteria, in its final version. São Paulo, SP, Brazil, 2016

\begin{tabular}{|c|c|c|c|c|}
\hline \multirow{2}{*}{ Item / nursing care } & \multicolumn{4}{|c|}{ Evaluation criteria } \\
\hline & Clarity & Relevance & Pertinence & Completeness \\
\hline \multicolumn{5}{|l|}{ Before induction } \\
\hline $\begin{array}{l}\text { A) Operation of anesthesia equipment } \\
\text { 1) Perform the anesthesia equipment test according to the manufacturer's } \\
\text { instructions, also verifying: connection of the equipment to the source of } \\
\text { energy and battery, source of gases (oxygen, nitrous oxide, compressed } \\
\text { air and vacuum) available, connected to the equipment and with pressure } \\
\geq 50 \mathrm{Psi}^{*} \text { or } 3.2 \mathrm{kgf} / \mathrm{cm}^{2 \dagger} \text {, full and closed vaporizers, no gas oscillation with } \\
\text { closed flowmeters. }\end{array}$ & 80 & 100 & 100 & 100 \\
\hline 2) Provide a set of breathing circuit according to the patient's age range & 100 & 100 & 100 & 100 \\
\hline $\begin{array}{l}\text { 3) Evaluate the saturation (color) of the soda lime and consider the exchange } \\
\text { if more than } 50 \% \text { is violet }\end{array}$ & 100 & 100 & 100 & 100 \\
\hline $\begin{array}{l}\text { 4) Blood pressure cuff, according to the patient's physical characteristics } \\
\text { (weight, age) }\end{array}$ & 100 & 100 & 100 & 100 \\
\hline $\begin{array}{l}\text { 5) Adjust multi-parameter monitor alarms, according to the age range of the } \\
\text { patient }\end{array}$ & 80 & 100 & 100 & 100 \\
\hline \multicolumn{5}{|l|}{ D) Airway material } \\
\hline $\begin{array}{l}\text { 6) Separate endotracheal tube, according to the patient's physical } \\
\text { characteristics (age, gender) and type of surgery, consider the availability of } \\
\text { three different sizes }\end{array}$ & 100 & 100 & 100 & 100 \\
\hline \multicolumn{5}{|l|}{ E) Organize materials for intubation } \\
\hline $\begin{array}{l}\text { 7) air cushion mask, according to the physical characteristics of the patient } \\
\text { (weight, age) }\end{array}$ & 100 & 100 & 100 & 100 \\
\hline 8) Gastric probe: children from 4 to $10 \mathrm{Fr}^{\ddagger} /$ adults from 14 to $18 \mathrm{Fr}^{\ddagger}$ & 100 & 100 & 100 & 100 \\
\hline \multicolumn{5}{|l|}{ F) Difficult airway } \\
\hline $\begin{array}{l}\text { 9) Availability of tracheostomy cannula, according to the patient's physical } \\
\text { characteristics (weight, age) }\end{array}$ & 80 & 80 & 80 & 80 \\
\hline $\begin{array}{l}\text { 10) Availability of esophageal-tracheal tube (combitube), according to the } \\
\text { patient's physical characteristics (height) }\end{array}$ & 100 & 100 & 100 & 100 \\
\hline \multicolumn{5}{|l|}{ Anesthetic induction } \\
\hline \multicolumn{5}{|l|}{ C) Monitor the patient with } \\
\hline 11) Thermometer & 80 & 100 & 100 & 80 \\
\hline
\end{tabular}




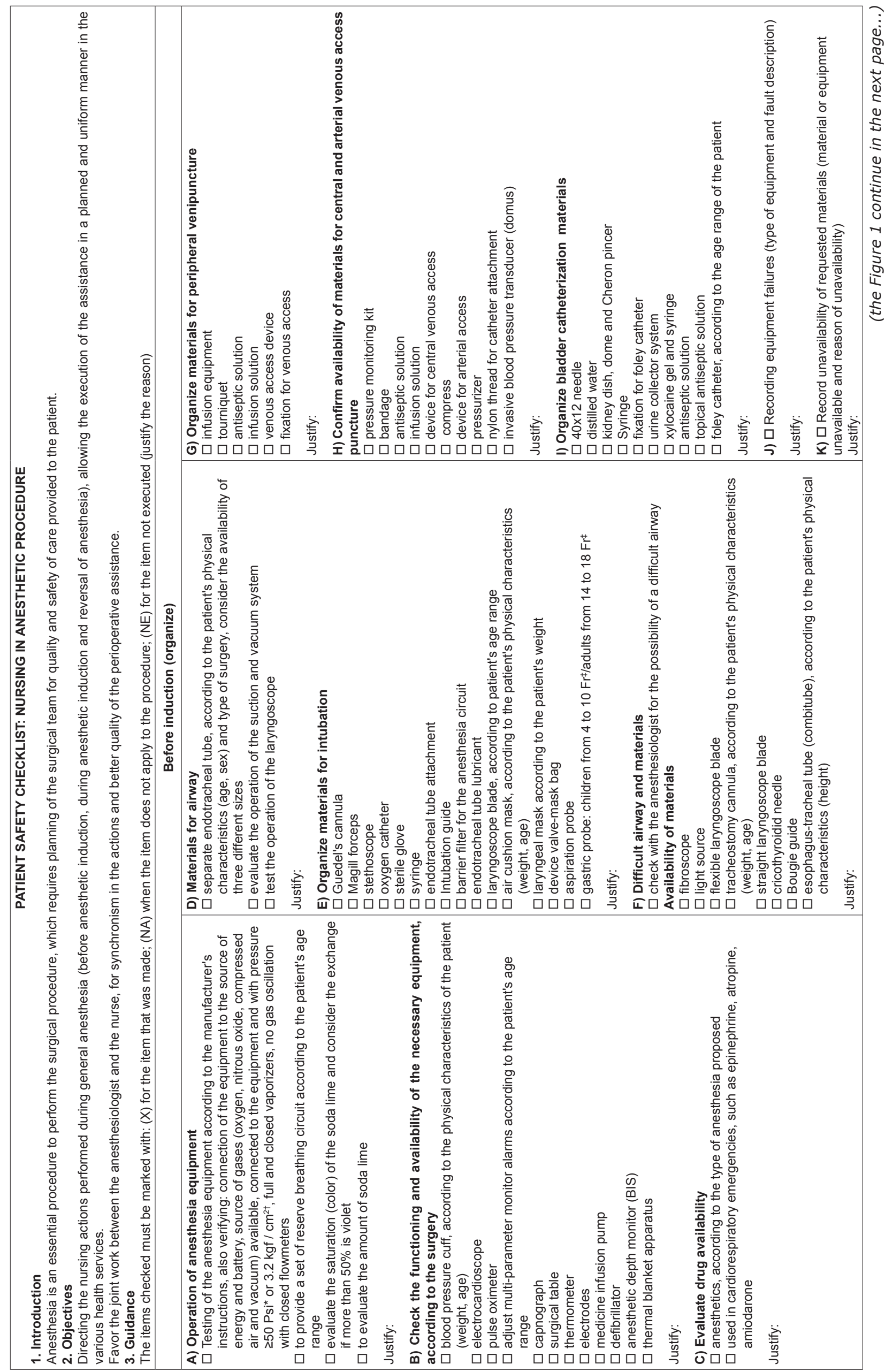



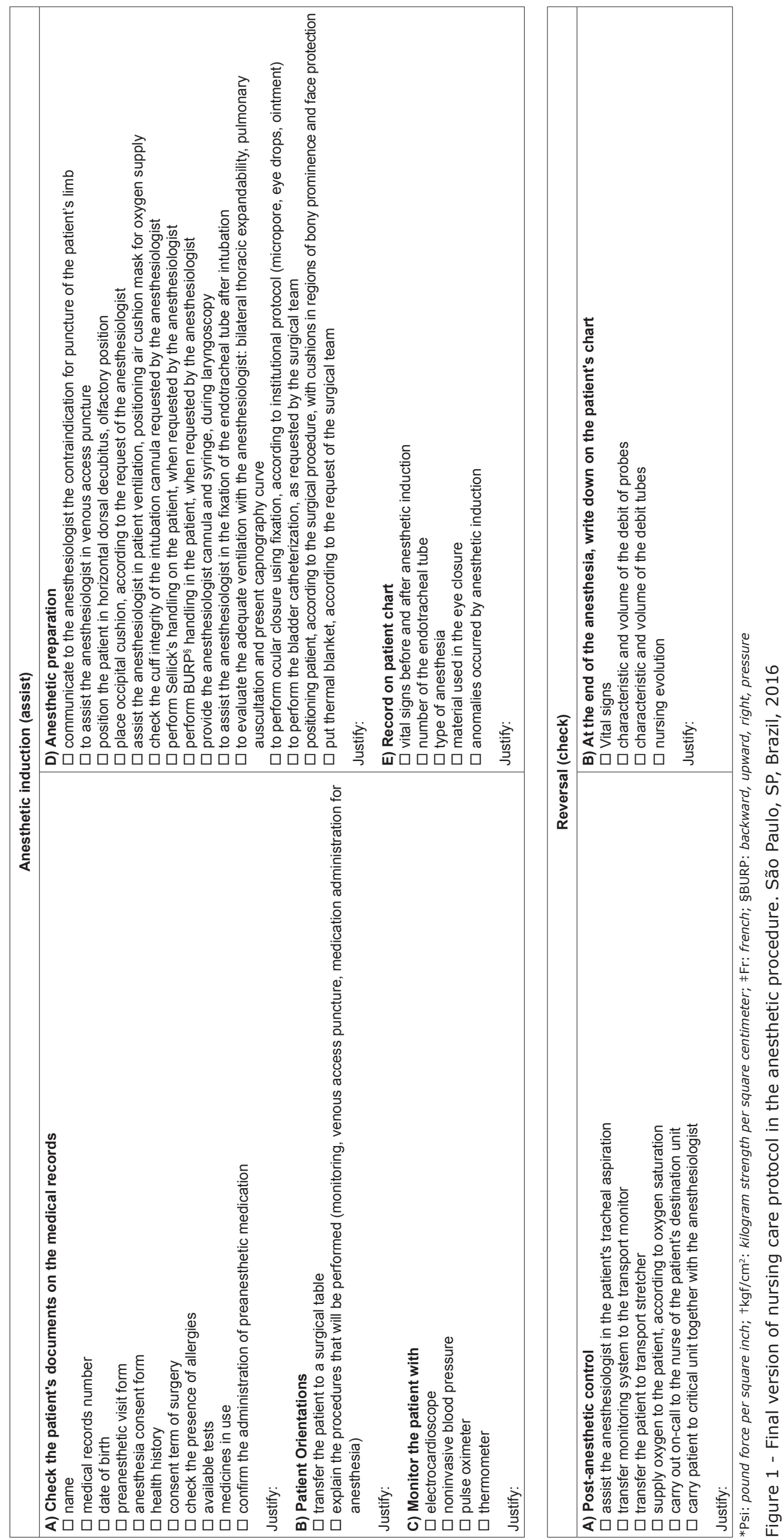


\section{Discussion}

The results indicated a good agreement between the items evaluated by the specialists, considering that only $9.2 \%$ generated some type of disagreement and the divergences were mainly related to the criteria of choice, availability and selection of materials for the anesthetic procedure in the pre-induction period.

Most of the items of the induction period and all items of anesthesia reversal were considered valid by the specialists, affirming the importance of the care performed by the nurse in a surgical room.

The standardization of care offered by nursing during the anesthetic act contributes to the determination of the nursing role within this area, establishing a package of actions legally allowed in the country.

In Brazil, care and performance standards are clear for anesthesiologists ${ }^{(11-12)}$. The physician should perform the pre-anesthetic visit to evaluate patient risk factors, such as blood loss greater than $500 \mathrm{ml}$ during surgery, assessment of the anatomy of the mouth and difficulty in intubation, according to Mallampati's classification, risk of aspiration or airway allergies, alterations of tests, comorbidities and medications in use ${ }^{(11-12)}$.

During anesthesia-surgical procedure, the presence of an anesthesiologist is required in the surgical room, the supply of supplemental oxygen to patients undergoing general anesthesia, monitoring of oxygen saturation by pulse oximetry and ventilation, circulation control and heart rate monitoring, measurement of blood pressure every five minutes, body temperature measurement and regular evaluation of anesthetic depth by clinical observation ${ }^{(11-12)}$.

All these measures seek to prevent adverse events. Thus, it is considered that the definition of care standards, with the identification of potential risks and necessary measures for the safety of interventions, combined with inter-professional work and good communication, can improve health care processes and outcomes (41-42).

In 1993, the American Society of Anesthesiologists (ASA), aiming at the adequate planning of anesthesia care and reduction of postoperative morbidity and mortality, considering the reality of each health service and the types of equipment available, developed a checklist, revised in 2008, which contained actions for execution before anesthetic induction ${ }^{(43)}$.

The checklist suggested items, some of which are also covered by this protocol, such as the anesthesia equipment operating test, soda lime check, auxiliary oxygen supply availability and bag-valve-mask device, vacuum for aspiration, availability of monitoring system and alarms, with emphasis on pulse oximetry and capnography, verification of the flow of gases and adequate pressure for ventilation in the anesthesia equipment, as well as the registration of any conference procedure $^{(43)}$.

It is worth noting that WHO recommends minimum standards of assistance/care in anesthesia during anesthesia-surgical procedures. They involve the planning of materials and medicines in health services, equipment testing, monitoring care, according to the complexity of the clientele served and the hospital institution. These measures can be defined as highly recommended, recommended and suggested ${ }^{(11-12)}$.

The highly recommended standards in anesthesia are mandatory standards, that is, applicable to all types of institutions that perform procedures under anesthesia, from small hospitals to referral hospitals.

Therefore, several items contemplated in the protocol must be properly checked and recorded, among them the availability and operation of materials in the operating room and materials for airway (masks, working laryngoscopes, endotracheal tubes, intubation guide (Bougie), oral and nasopharyngeal Guedel cannula, aspiration system and humidifiers), evaluation of anesthesia equipment (gas flow and pressure, soda lime color check, circular system with test balloons, full and closed oxygen cylinder, filled and adjusted vaporizers), (Lignocaine, diazepam, midazolam, morphine, adrenaline, atropine, inhaled anesthetics), blood and fluids available, monitors with alarms attached, stethoscope, sphygmomanometer and thermometer ${ }^{(11-12)}$.

Studies have shown that the use of checklists for the organization of anesthetic induction care can assist in the detection of errors and negligence in relation to care, reducing failures during anesthesia and surgery, by means of appropriate equipment and material checks, in addition to promoting the exchange of information among professionals about the clinical conditions of the patient and critical aspects such as allergies and difficult airway, thus improving the perception of professionals about teamwork and prevention of damages, aspects that, together, contribute for patient safety(44-46).

All the professionals aligned with the scientific basis that guides the care to be performed, as well as the definition of limits and performance roles, contribute to a greater synchronism between the anesthetic procedure and the activities, and, therefore, 
a greater probability of success interventions. As a limitation, in this study, no pilot-application of the protocol was performed.

\section{Conclusion}

The nursing care protocol in anesthesia was validated with good agreement among specialists, and $90.8 \%$ of the items were considered adequate in the first round.

The nursing care protocol was developed within the limits of professional performance, without overlapping functions or violation of the law of professional practice, and can guide the role of the nurse during anesthesia. With this, it is possible to standardize care behaviors in different institutions, guaranteeing greater support to nurses in their performance in the anesthetic procedure, with the anesthesiologist.

It is emphasized that the nurse's use of the care protocol should be linked to the existence of systematized technical and scientific knowledge about the actions to be performed during anesthesia, stating the importance of their presence in a surgical room for care activities.

Thus, it is believed that this direction of nursing work, in anesthesia, can evidence the importance of nurses' work in a surgical center, even in the face of the difficulties experienced in the performance of roles within health institutions and in interaction with the medical team.

Future work is needed to evaluate the practical application and feasibility of using the care protocol in different realities.

\section{References}

1. Palmer L. Anesthesia 101: everthing you need to know. Plast Surg Nurs [Internet]. 2013 [cited 2017 Mar 9];33 (4): 164-71. Available from: https://www.ncbi. nlm.nih.gov/pubmed/24297077

2. Nunes RR. Anesthetic activity componentes- a new approach. Rev Bras Anestesiol. [Internet]. 2003 [cited 2017 Jul 1]; 53(2): 145-9. Available from: http:// www.scielo.br/scielo.php?script=sci_arttext\&pid =S0034-70942003000200001

3. Yektas A, Gumus F, Alagol A. Dexmedetomidine and propofol infusion on sedation characteristics in patients undergoing sciatic nerve block in combination with femoral nerve block via anterior approach. Rev Bras Anestesiol. [Internet]. 2015 [cited 2017 Jul 1]; 65(5): 371-8. Available from: http://www.scielo.br/pdf/rba/ v65n5/1806-907X-rba-65-05-00371.pdf

4. Haller G, Laroche T, Clergue F. Morbidity in anaesthesia: today and tomorrow. Best Pract Res Clin Anaesthesiol. [Internet]. 2011 [cited 2017 Jul 02];
25(2):123-32. Available from: https://www.ncbi.nlm. nih.gov/pubmed/21550538

5. Davenport DL, Henderson WG, Mosca CL, Khuri SF, Mentzer RJ. Risk-adjusted morbidity in teaching hospitals correlates with reported levels of communication and collaboration on surgical teams but not with scale measures of teamwork climate, safety climate, or working conditions. J Am Coll Surg. [Internet]. 2007 [cited 2017 Jul 2]; 205(6):778-84. Available from: https://www.ncbi.nlm.nih.gov/pubmed/18035261

6. Metzner J, Posner KL, Lam MS, Domino KB. Closed claims' analysis. Best Pract Res Clin Anaesthesiol. [Internet]. 2011 [cited 2017 Jul 1]; 25(2):26376. Available from: https://www.ncbi.nlm.nih.gov/ pubmed/21550550

7. Staender S. Incident reporting in anaesthesiology. Best Pract Res Clin Anaesthesiol. [Internet]. 2011 [cited 2017 Feb 3]; 25: 207-14. Available from:

https://www.ncbi.nlm.nih.gov/pubmed/21550545

8. Braz LG, Braz DG, Cruz DS, Fernandes LA, Modolo NS, Braz JR. Mortality in anesthesia: a systematic review. Clinics. (Sao Paulo) [Internet]. 2009 [cited 2017 Jul 1]; 64(10):999-1006. Available from: http://www.scielo.br/ scielo.php?pid=S1807-59322009001000011\&script $=$ sci arttext

9. Bainbridge D, Martin J, Arango M, Cheng D. Perioperative and anaesthetic-related mortality in developed and developing countries: a systematic review and meta-analysis. Lancet. [Internet]. 2012 [cited 2017 Jun 30]; 380(9847):1075-81. Available from: https:// www.ncbi.nlm.nih.gov/pubmed/22998717

10. Institute of Medicine. To err is human: building a safer health system. [Internet]. 1999

[cited 2015 Dec 9]. Available from:http://iom. nationalacademies.org/Reports/1999/To-Err-is-HumanBuilding-A-Safer-Health-System.aspx.

11. Merry AF, Cooper JB, Soyannwo O, Wilson IH, Eichhorn JH. International standards for a safe practice of anesthesia 2010. Can J Anaesth. [Internet]. 2010 [cited 2013 Apr 29]; 57 (11): 1027-34. Available from: https://www.ncbi.nlm.nih.gov/pubmed/20857254

12. World Health Organization. Second Global Challenge for Patient Safety: Safe Surgeries Save Lives (Guidelines for Safe Surgery from WHO) World Health Organization. Pan American Health Organization; Ministry of Health; National Health Surveillance Agency]. Rio de Janeiro; [Internet]. 2009. Portuguese. [cited 2016 May 31]. Available from: http://bvsms.saude.gov.br/bvs/publicacoes/seguranca_ paciente_cirurgia_salva_manual.pdf

13. Mayer EK, Sevdalis N, Rout S, Caris J, Russ S, Mansell J, et al. Surgical checklist implementation project: the impact of variable WHO checklist compliance on riskadjusted clinical outcomes after national implementation: a longitudinal study. Ann Surg [Internet]. 2016 [cited 2017 Jan 4]; 263 (1): 58-63. Available from: https:// www.ncbi.nlm.nih.gov/ pubmed/25775063 
14. Haugen AS, Softeland E, Eide GE, Sevdallis N, Vincent $C A$, Nortvedt MW, et al. Impact of the world health organization's surgical safety checklist on safety culture in the operating theatre: a controlled intervention study. $\mathrm{Br}$ ] Anaesth. [Internet]. 2013 [cited 2017 Jan 4]; 110 (5): 807-15. Available from: https://www.ncbi.nlm.nih. gov/pmc/articles/PMC3630285/

15. Kawano T, Taniwaki M, Ogata K, Sakamoto M, Yokoyama $M$. Improvement of teamwork and safety climate following implementation of the WHO surgical safety checklist at a university hospital in Japan. J Anesth. [Internet]. 2014 [cited 2017 Jan 19]; 28: 46770. Available from: https://www.ncbi.nlm.nih.gov/ pubmed/24170220

16. Haynes AB, Weiser TG, Berry WR, Lipsitz SR, Breizat AHS, Dellinger EP, et al. Changes in safety attitude and relationship to decreased postoperative morbidity and mortality following implementation of a checklist-based surgical safety intervention. BMJ Qual Saf. [Internet]. 2011[cited 2016 Apr 20]; 20:102-07. Available from: https://www.ncbi.nlm.nih.gov/pubmed/ 21228082

17. Pimenta CAM, Pastana ICASS, Sichieri K, Solha RKT, Souza W. [Guidelines for the construction of nursing care protocols]. Coren-SP. São Paulo; 2015. Portuguese. [cited 2017 Jan 10]. Available from: http://portal. corensp.gov.br/sites/default/files/

guia\%20construção\%20protocolos\%2025.02.14.pdf 18. Woolf S, Schunemann HJ, Eccles MP, Grimshaw JM, Shekelle P. Developing clinical practice guidelines: types of evidence and outcomes; values and economics, synthesis, grading, and presentation and deriving recommendations. Implementation Sci. [Internet]. 2012 [cited Jan 3]; 7:61. Available from: https://implementationscience.biomedcentral.com/ articles/10.1186/1748-5908-7-61

19. [12.842 Law of July 10, 2013. Provides for the practice of medicine]. Presidency of the Republic. Civil House Sub-Office for Legal Affairs (Jul 10, 2013). [Internet]. Portuguese [cited 2014 Out 22]. Available from: http://portal.cfm.org.br/index. php?option $=$ com_ content\&view $=$ article\&id $=24023$ : lei12842\&catid $=66$ : leis\&Itemid $=34$.

20. Plaus K, Muckle TJ, Henderson JP. Advancing recertification for nurse anesthetists in an environment of increased accountability. AANA J. [Internet]. 2011 [cited 2013 Mar 13]; 79 (5): 413-8. Available from: https://www.aana.com/newsandjournal/Documents/ advrecert_1011_p413-418.pdf

21. Neft M, Quraishi JA, Greenier E. A closer look at the standards for nurse anesthesia practice. AANA J. [Internet]. 2013 [cited 2014 Feb 13]; 81(2):92-6. Available from: https://www.ncbi.nlm.nih.gov/pubmed/23971226

22. Meeusen V, Zundert AV, Hoekman J, Kumar C, Rawal $\mathrm{N}$, Knape $\mathrm{H}$. Composition of the anaesthesia team: a European survey. Eur J Anaesthesiol. [Internet]. 2010 [cited 2017 Mar 12]; 27(9):773-9. Available from: https://www.ncbi.nlm.nih.gov/pubmed/20671555.
23. Schmidt DRC, Dantas RAS, Marziale MHP, Laus AM. Occupational stress among nursing staff in surgical settings. Texto Contexto Enferm. [Internet]. 2009 [cited 2017 Jul 2]; 18 (2): 330-7. Portuguese. Available from: http://www.scielo.br/pdf/tce/v18n2/17.pdf

24. Martins FZ, Dall'agnol CM. Surgical center: challenges and strategies for nurses in managerial activities. Rev Gaúcha Enferm. [Internet]. 2016 [cited 2017 Jul 1]; 37(4):18. Portuguese. Available from: http://www.scielo.br/ scielo.php?pid=S1983-14472016000400415\&script $=$ sci_ arttext

25. Possari JF, Gaidzinski RR, Lima AFC, Fugulin FMT, Herdman TH. Use of the nursing intervention classification for identifying the workload of a nursing team in a surgical center. Rev. Latino-Am. Enfermagem. [Internet]. 2015 [cited 2017 Jun 30]; 23(5):781-8. Available from: http://www.scielo.br/readcube/epdf. php?doi=10.1590/0104-1169.0419.2615\&pid=S0104$11692015000500781 \&$ pdf_path $=$ rlae/v23n5/01041169-rlae-23-05-00781.pdf\&lang=en

26. Castellanos BEP, Jouclas VMG. Assistência de enfermagem perioperatória: um modelo conceitual. Rev Esc Enferm USP. [Internet]. 1990 [cited 2017 Jun 30]; 24 (3):359-70. Available from: http://www.scielo.br/ pdf/reeusp/v24n3/0080-6234-reeusp-24-3-359.pdf.

27. Curi C, Peniche ACG. Nurse anestesia practice: a profound study of the perioperative nurse. Rev SOBECC. [Internet]. 2004 [cited 2017 Jul 2]; 9(3):8-13. Available from: https://revista.sobecc.org.br/sobecc/issue/ viewIssue/52/pdf_24

28. Fonseca RMP, Peniche ACG. Operation room nursing in Brazil: thirty years after the Institution of Perioperative Nursing Process. Acta Paul Enferm. [Internet]. 2009 [cited 2017 Jun 29]; 22(4): 428-33. Portuguese. Available from: http://www.scielo.br/scielo.php?script=sci_arttex t\&pid $=$ S0103-21002009000400013

29. Lemos CS, Peniche ACG. [Nursing care in the anesthetic procedure: an integrative review]. Rev Esc Enferm USP. [Internet]. 2016 [cited 2016 Mar 25]; 50(1):154-62. Portuguese. Available from: https:// www.ncbi.nlm.nih.gov/pubmed/27007433

30. Vickers MD. Anaesthetic team and the role of nurseseuropean perspective. Best Pract Res Clin Anaesthesiol. [Internet]. 2002 [cited 2014 Jul 30]; 16(3):409-21. Available from: http://doi.org.ololo.sci-hub.cc/10.1053/ bean.2001.0223

31. Neft M, Okechukwu K, Grant P, Reede L. The revised scope of nurse anesthesia practice embodies the broad continuum of nurse anesthesia services. AANA J. [Internet]. 2013 [cited 2014 Jul 30]; 81(5): 347-50. Available from: https://www.ncbi.nlm.nih.gov/ pubmed/24354069

32. [ 7.498 Law of June 25, 1986. Provides for the practice of nursing]. Presidency of the Republic. Civil House Sub-Office for Legal Affairs (June 25, 1986). [Internet]. Portuguese [cited 2017 Jul 3]. Available from: http://www.planalto.gov.br/ccivil_03/leis/L7498.htm 
33. Lemos CS. Nursing assistance to the anesthetic procedure: patient safety protocol [Internet] [dissertation]. São Paulo (SP): São Paulo University; 2015. [cited 2017 Mar 9]. Available from: http://www. teses.usp.br/teses/disponiveis/7/7139/tde-13102015161656/pt-br.php.

34. Furr RM, Bacharach VR. Psychometrics: na introduction. 2nd ed. Los Angeles: Sage; 2014. p. 197220. [cited 2017 Jul 3]. Available from: https://books. google.com.br/books?hl=pt-BR\&lr=\&id=FjQ3VG2cBtgC $\& o i=f n d \& p g=P P 1 \& d q=F u r r+R M,+$ Bacharach +VR. +Psy chometrics: + an + introduction\&ots $=$ Lb1WIk0Rm0\&sig $=$ Rrni4tr5IwUjPxda-6yNIsW-YmM\#v=onepage\&q\&f=false 35. Devellis, RF. Scale development. Theory and applications. $4^{\mathrm{a}}$ ed. Los Angeles: Sage; 2017. p. 106-51. [cited 2017 Jul 3]. Available from: https://books.google. com. br/books? $\mathrm{hl}=\mathrm{pt}-\mathrm{BR} \& \mathrm{lr}=\& \mathrm{id}=48 \mathrm{ACC}$ AAQBAJ\&oi $=\mathrm{f}$ nd\&pg=PT14\&dq=Devellis, + RF. + Scale+development. + Theory+and+applications. $+4 \% \mathrm{C} 2 \% \mathrm{AA}+$ ed. +Los+Angel es: +Sage\%3B+2017.\&ots=K_3Qx5KaQr\&sig=bA_VOvV omvIu3ENeW0tjfST7MBM\# $v=$ onepage $\& q \& f=$ false

36. Grant JS, Davis LL. Selection and use of contente experts for instrument development. Res Nurs Health. [Internet]. 1997 [cited 2015 Feb 18]; 20: 26974. Available from: https://www.ncbi.nlm.nih.gov/ pubmed/9179180

37. Rubio DM, Weger MB, Tebb SS, Lee ES, Rauch S. Objectifying content validity: Conducting a content validity study in social work research. Soc Work Res. [Internet]. 2003 [cited 2015 Oct 26]; 27(2): 94-105. Available from: //doi.org/10.1093/swr/27.2.94

38. Polit DF, Beck CT, Owen SV. Is the CVI an Acceptable Indicator of Content Validity? Appraisal and Recommendations. Res Nurs Health. [Internet]. 2007 [cited 2017 Jun 29]; 30(4):459-67. Available from: http://onlinelibrary.wiley.com/doi/10.1002/nur.20199/full.

39. Alexandre NMC, Coluci MZO. [Content validity in the development and adaptation processes of measurement instruments]. Ciênc. Saúde Coletiva. [Internet]. 2011 [cited 2016]ul 12]; 16(7): 3061-68. Portuguese. Available from: http://www.scielo.br/ scielo.php?script=sci_artte $\mathrm{xt} \& \mathrm{pid}=\mathrm{S} 1413-81232011000800006$

40. Polit DF, Beck CT. The content validity index: are you sure you know what's being reported? Critique and recommendations. Res Nurs Health. [Internet]. 2006 [cited 2015 Feb 3]; 29: 489-497. Available from: https://www.ncbi.nlm.nih.gov/pubmed/16977646 41. Sangaleti CT, Schveitzer MC, Peduzzi M, Zoboli ELCP, Soares CB. The experiences and shared meaning of teamwork and interprofessional collaboration to health care professionals in primary health care settings: a systematic review protocol. JBI Database System Rev Implement Rep. [Internet]. 2014 [cited 2017 Jan 3]; 12(5) 24- 33. Available from: http://joannabriggslibrary. org/index.php/jbisrir/article/view/1086

42. Catchpole K, Mishra A, Handa A, Mcculloch P. Teamwork and error in the operating room - analysis of skills and roles. Ann Surg. [Internet]. 2008 [cited 2015 Mar 20]; 247 (4): 699-706. Available from: https:// www.ncbi.nlm.nih.gov/pubmed/18362635

43. Brockwell RC, Dorsch J, Dorsch S, Eisenkraft J, Feldman J, Holland CG, et al. Recommendations for preanesthesia checkout procedures. Guideline for Designing Pre-Anesthesia Checkout Procedures. [Internet]. 2008 [cited 2017 Jan 11]. Available from:https://www. asahq.org/resources/clinical-information/2008-asarecommendations-for-pre-anesthesia-checkout.

44. Blike G, Biddle C. Preanesthesia detection of equipment faults by anestesia providers at an academic hospital: comparison of standard practice and a new eletronic checklist. AANA J. [Internet]. 2000 [cited 2017 Feb 1]; 68 (6): 497-304. Available from: http:// europepmc.org/abstract/med/11272956

45. Krombach JW, Marks JD, Dubowitz, G, Radke OC. Development and implementation of checklists for routine anesthesia care: a proposal for improving patient safety. Anesth Analg [Internet]. 2015 [cited 2016 Apr 20];121(4): 1097-102. Available from: http://journals. Iww.com/anesthesiaanalgesia/Citation/2015/10000/ Development_and_Implementation_of_Checklists_ for.32.aspx

46. Tscholl DW, Weiss M, Kolbe M, Staender S, Seifert $B$, Landert $D$, et al. An anesthesia preinduction checklist to improve information Exchange, knowledge of critical information, perception of safety, and possibly perception of teamwork in anestesia teams. Anesth Analg. [Internet]. 2015 [cited 2016 Apr 20]. 121 (4): 948-56. Available from: https://www.ncbi.nlm.nih.gov/ pubmed/25806
Corresponding Author:

Cassiane de Santana Lemos

Universidade de São Paulo Escola de Enfermagem

Av Dr Eneas de Carvalho Aguiar, 419

Bairro: Pinheiros

CEP: 05403-000, São Paulo, SP, Brasil

E-mail: cassilemos@usp.br; cassifest@gmail.com
Received: Mar $12^{\text {th }} 2017$

Accepted: Aug. $27^{\text {th }} 2017$
Copyright $\odot 2017$ Revista Latino-Americana de Enfermagem This is an Open Access article distributed under the terms of the Creative Commons (CC BY).

This license lets others distribute, remix, tweak, and build upon your work, even commercially, as long as they credit you for the original creation. This is the most accommodating of licenses offered. Recommended for maximum dissemination and use of licensed materials. 